\title{
VALORES ATRIBUÍDOS AO TRABALHO E EXPECTATIVA DE FUTURO: COMO OS JOVENS SE POSICIONAM?
}

\author{
VALUES ATTRIBUTED TO WORK AND EXPECTATIONS FOR THE FUTURE: HOW YOUNG PEOPLE \\ POSITION THEMSELVES?
}

\author{
Sheila Aparecida Ferreira Lachtim ${ }^{1}$ \\ Cássia Baldini Soares ${ }^{2}$
}

Resumo A inserção dos jovens no mundo do trabalho vem sendo matizada pela reestruturação produtiva, fenômeno que situa o trabalho e o futuro em patamares cada vez mais instáveis e inseguros. Partindo da consideração teórica de que valores são histórica e socialmente situados, e que a ideologia liberal sobre o trabalho impregna a vida social, o objetivo desta investigação foi identificar e analisar os valores atribuídos ao trabalho por jovens de diferentes grupos sociais. Trata-se de uma pesquisa qualitativa que apreendeu o objeto empírico por meio da análise de conteúdo de entrevistas com 86 jovens de diferentes grupos sociais de um município da região metropolitana de São Paulo. De modo geral, os jovens de todos os grupos percebem o trabalho como algo valoroso, essencial para o crescimento e amadurecimento que se espera na fase adulta. Houve diferentes posicionamentos entre os grupos sociais quanto à finalidade do trabalho, variando entre caminho para a realização de valores de consumo e posição social e meio para suprir necessidades básicas de sobrevivência. Porém, a ideologia liberal sobre inserção no trabalho marcou todos os grupos. O futuro encontra-se condicionado ao rumo que tomarem no mercado de trabalho, meio principal para conseguir realizar os sonhos.

Palavras-chave juventude; trabalho; valores sociais; pesquisa qualitativa.
Abstract The integration of young people to the labor world has been colored by the restructuring of production, a phenomenon that ranks both work and the future at increasingly unstable and insecure levels. Based on the theoretical consideration that social values are historically and socially situated, and that the liberal ideology of work pervades social life, this investigation aimed to analyze the work values of young people from different social groups. It is a qualitative study that captured the empirical object by analyzing the content of interviews carried out with 86 young people from different social groups in a municipality located in the São Paulo metropolitan region. In general, young people from all groups perceive work as something that is valuable, essential to attain the growth and maturation that is expected in adulthood. The purpose of the study proved to be a little different, since while for some work is the means through which it is possible to achieve the values of consumption and social position, to others it is a means to meet basic survival needs. Thus, the future depends on the direction they take in the labor market, since this is believed to be the main means to materialize other dreams.

Keywords youth; work; social values. 


\section{Introdução}

O mundo do trabalho atual constitui grande desafio para os jovens. Relatório recente da Organização Internacional do Trabalho (OIT) (Costanzi, 2009), que trata da relação juventude e trabalho, reconhece que a inserção dos jovens no mundo do trabalho se faz de maneira precária, visto que os índices de 'trabalho decente' 3 são baixos. O jovem sofre com a informalidade, as baixas remunerações e o desemprego, mecanismos que alimentam um ciclo imprevisível de desproteção social. Além da precarização do trabalho, o jovem tem que encarar o desemprego, cuja taxa é maior entre os jovens do que entre os adultos. ${ }^{4}$ Distribuídos de forma heterogênea, os jovens de famílias com renda per capita de até um salário mínimo são os mais excluídos do mercado de trabalho, o que torna o processo de exclusão social ainda mais severo.

Neste trabalho, parte-se da compreensão teórica de que, com o desenvolvimento do capitalismo, sentido e valor do trabalho foram transformados em mercadoria passível de ser comprada. Essa mediação considerada de segunda ordem leva a uma "completa subordinação das necessidades humanas à reprodução do valor de troca - no interesse da autorrealização expansiva do capital" (Antunes, 1999, p. 21).

Em outras palavras, a mercadoria força de trabalho, diferente das outras, é atributo de um ser humano. Contudo, em uma sociedade que é uma coleção de mercadorias, a pessoa cujos atributos não encontram compradores, tal como o cimento não vendido, será descartada. A sociedade capitalista é capitalista porque substitui, como motor de sua reprodução, o humano pelo capital (Lessa, 2006, p. 240).

Na fase da acumulação flexível, a reestruturação produtiva se vale de 'novos' modos de valorizar o trabalho, de forma que não se propõe como satisfatório o desenvolvimento de uma carreira baseada na ascensão a melhores postos dentro da empresa, na disciplina no trabalho e na substituição dos prazeres da vida pelo sacrifício da dedicação ao trabalho. Toda essa moral do trabalho perde espaço na cultura do 'novo' mundo do trabalho, assumindo importância a competição entre equipes, a excitação da migração de uma tarefa para outra, de um emprego para outro. O prestígio moral do trabalho se modifica a tal ponto que somente a tarefa do dia faz sentido (Sennett, 2008).

Dessa forma, pode-se afirmar que, sob o regime de acumulação flexível, a reestruturação produtiva reitera, no plano estrutural, a valorização do trabalho como mercadoria, força de trabalho, mas estabelece 'novas' formas de trabalhar. Já na dimensão superestrutural, ideológica, no plano simbólico, que a tudo invade para sustentar as relações capitalistas de produção, o tra- 
balho passa a ser representado pelas noções de polivalência, competência e empregabilidade (Frigotto, Ciavatta, 2003).

No senso comum e dentro da vulgata neoliberal, hoje, trabalho e trabalhador produtivos estão profundamente permeados pela ideia de que é aquele que faz, produz mais rapidamente, tem qualidade ou é mais competente. $\mathrm{O}$ fulcro central das visões apologéticas de produtividade e de trabalho produtivo resulta na ideia de que cada trabalhador é socialmente remunerado ou socialmente valorizado para manter-se empregado ou não, de acordo com sua produtividade, vale dizer, de acordo com a sua efetiva contribuição para a sociedade. Ou seja, o que o trabalhador ganha corresponde ao que contribui, e o que cada um tem em termos de riqueza depende de seu mérito, de seu esforço (Frigotto e Ciavatta, 2003, p. 50).

Os países da periferia do capitalismo de industrialização intermediária, como os da América Latina, presenciam repercussões ainda mais graves dos processos de desindustrialização, que resultam na "expansão do trabalho precarizado, parcial, temporário, terceirizado, informalizado etc., além de enormes níveis de desemprego" (Antunes, 2003, p. 3).

Partindo do pressuposto de que os jovens brasileiros vêm sendo particularmente afetados pela reestruturação produtiva e que os valores dos jovens sobre trabalho, histórica e socialmente circunstanciados, encontramse impregnados pela lógica neoliberal que perpassa a sociedade em geral e o mundo do trabalho, em particular, este estudo objetiva analisar os valores atribuídos ao trabalho de jovens de diferentes grupos sociais em sua relação com a expectativa de futuro.

\section{Metodologia}

Trata-se de uma pesquisa qualitativa realizada na cidade de Santo André, região metropolitana de São Paulo. Integrando a região do grande $\mathrm{ABC}$, o município foi escolhido porque se apresenta marcado historicamente, de um lado, por processos intensos de industrialização e, de outro, pela liderança na implementação de políticas públicas voltadas à juventude (Almeida, Villar, 2005).

Serviu de base metodológica para este estudo o Mapa das Juventudes de Santo André (Yonekura et al., 2010), que dividiu o município em quatro regiões, a partir da análise de um conjunto expressivo de variáveis sociais e econômicas, disponibilizadas pelo IBGE (Censo demográfico, 2000), relativas à reprodução social dos jovens, tais como: características gerais, migração, instrução, nupcialidade, fecundidade, trabalho e rendimento, características domiciliares e de saneamento, e potencial de consumo. Cada região 
foi composta por semelhança quanto a essas características, de forma que as melhores frequências de acesso a bens e serviços encontravam-se no grupo da região central e as piores no grupo da região periférica. As regiões foram assim denominadas: central (C), quase-central (QC), quase-periférica (QP) e periférica $(\mathrm{P})$.

Com a participação da secretaria municipal de saúde do município, realizou-se um levantamento das instituições que trabalhavam com jovens em cada uma dessas regiões, selecionando-se algumas escolas, centros de formação profissional e clubes de lazer, julgados representativos de cada uma das regiões. A população de estudo foi composta por jovens entre 20 e 24 anos moradores das quatro regiões e que frequentavam essas instituições. Procurou-se manter certa proporcionalidade entre o número de participantes da pesquisa e o número de jovens em cada uma das regiões.

Dessa forma, 86 jovens foram entrevistados, sendo 15 na região C, 21 na QC, 23 na QP e 27 na P. Neste trabalho se apresenta apenas os resultados relativos ao valor que os jovens atribuíram ao trabalho, sendo que em outros espaços são discutidos outros conjuntos de valores.

As entrevistas foram gravadas, transcritas e os dados analisados de acordo com as orientações de Bardin (1977), para análise temática, e de Triviños (1987), que toma como base metodológica de interpretação dos dados a corrente dialética, o que significa explorar o potencial qualitativo de interpretação das categorias empíricas a partir de categorias de análise predefinidas em um quadro teórico.

Dessa forma, neste trabalho tomou-se a categoria valores sociais como eixo para interpretar a realidade, compreendendo valorização como um processo histórica e socialmente construído durante a socialização humana, e como um processo que, dada a divisão social, potencialmente refletiria interesses de classes, porém crivados pela ideologia da classe dominante (Viana, 2007).

A pesquisa seguiu os fundamentos éticos legais da resolução n. 196/96, do Conselho Nacional de Saúde, tendo sido aprovada pelo Comitê de Ética em Pesquisa da Escola de Enfermagem da USP e pelo Comitê de Ética em Pesquisa da Secretaria Municipal de Saúde de Santo André, local de realização do estudo. Todos os jovens participaram voluntariamente da pesquisa, assinando um Termo de Consentimento Livre e Esclarecido.

\section{Resultados e discussão}

Os sujeitos da pesquisa encontravam-se majoritariamente na faixa de 20 a 24 anos. Dos 86 entrevistados, 38 eram do sexo feminino e 48 do sexo masculino. Os jovens da região C, em sua maioria (67\%), estavam cursando uma faculdade. Pertence também a esse grupo o único entrevistado que já tinha 
cursado uma pós-graduação. Dentre os jovens da região QC, a maior parte estava cursando terceiro grau (57\%). Nesses dois grupos não havia jovens apenas com o ensino fundamental. Nos grupos periféricos, vale ressaltar, a maioria estava cursando ensino supletivo, tanto correspondente ao ensino médio quanto ao ensino fundamental, sendo que, no grupo QP, 74\% encontravam-se no ensino médio, e no $\mathrm{P}$ chegavam a $82 \%$ os que cursavam o ensino médio. Observa-se também que $13 \%$ dos jovens da região QP estavam ainda no ensino fundamental, enquanto que na região $\mathrm{P}$ essa porcentagem subia para $18 \%$.

A maioria dos jovens de todos os grupos trabalhava, sendo que o grupo da região QP apresentou a maior proporção de jovens inseridos no mercado de trabalho, enquanto que o grupo da região $\mathrm{P}$ apresentou a maior proporção de desempregados. Já os jovens dos grupos C e QC não relataram problema com desemprego.

Os dados permitiram perceber ainda que, nos grupos mais centrais (C e QC), muitos começaram a trabalhar como estagiários, enquanto frequentavam uma faculdade, ou na profissão em que se formaram, após o término da faculdade. Os poucos que se inseriram precocemente no trabalho desenvolviam atividades junto aos negócios da família. As regiões periféricas (QP e P) apresentaram, em contraposição, as inserções mais precoces no trabalho.

Apresentam-se abaixo excertos dos discursos dos entrevistados representativos das interpretações realizadas. Cada trecho é atribuído a um entrevistado, identificado por E1, E2, E3 e assim por diante, e por C, QC, QP e $\mathrm{P}$, conforme o grupo social a que pertencem.

\section{O trabalho tem valor: da sobrevivência ao desejo de desfrutar de status social}

O trabalho nesta pesquisa adquiriu diferentes conotações a depender do grupo social, conformando-se nos grupos centrais como instrumento de obtenção de status social, e nos grupos periféricos como meio de sobrevivência das famílias, porém de maneira semelhante os jovens de todos os grupos relacionaram a necessidade de frequentar o ensino regular a uma boa colocação no mercado de trabalho.

Eu procurei emprego e tal e agora estou estagiando em uma empresa. Ah, tem responsabilidades, tem [que] atingir metas no mercado, conseguir status e um bom salário para se sustentar, ter as suas coisas para fazer. Pagar as suas contas, acho importante isso (E2, C).

Do meu trabalho eu gosto, é a minha área mesmo, você tem uma autonomia como profissional, pode controlar, pode fazer estudos, otimizar a produção, eu gosto 
mesmo, de poder manipular o processo. Estudar, conseguir uma colocação profissional diferente com a minha formação superior, comprar a minha casa (E19, QC).

Eu sou doméstica, mas também ao mesmo tempo eu sou dama de companhia. E faço curso de cabeleireira aqui na escola mesmo, que estudo (...) e essa é a minha atividade (...). Cheguei aqui em São Paulo aos 12 anos de idade (...) cada dia eu tenho um sonho, sabe... não de trabalhar só de doméstica, mas de trabalhar de uma outra coisa, sabe... ser uma secretária... Cada dia tenho um sonho de crescer. E eu vou correr, fazer tudo, para que meus objetivos se vejam realizados. E vão ser, porque eu sou muito esforçada (E38, QP).

Eu trabalho na feira, das duas da manhã até as 15 horas. Eu comecei a trabalhar com 18, na feira. Na verdade eu comecei a trabalhar mesmo com 10 anos... Eu ajudava ela a vender as coisas na rua... Ela vendia de tudo um pouco. Aí depois virei doméstica, quando tinha 15 anos, e agora com 18 fui trabalhar na feira. Problemas mesmo, minha mãe não conseguia emprego, surgiu essa oportunidade e eu fui, ganhava um salarinho e dava tudo para ela. Trabalhei para pagar as contas, comprar comida... Acho muito bom (...) porque você tem o seu dinheiro todo mês, você pode comprar as coisas que você quer e não precisa roubar para ter isso. Pelo menos você está trabalhando, você está dando o suor para conseguir o dinheiro. Não está conseguindo fácil (E30, P).

A pesquisa "Perfis da juventude brasileira", conforme analisada por Branco (2005), mostra que os jovens com baixa renda apresentam como principais motivos para o trabalho: necessidade (69\%), independência (53\%), crescimento ( $47 \%$ ) e autorrealização $(24 \%)$, ao passo que quando se analisam os motivos dos que contam com rendas maiores, verifica-se uma ordenação diferente: independência (57\%), crescimento (51\%), autorrealização $(47 \%)$ e necessidade (42\%). Em Santo André, os jovens das regiões mais centrais que já se encontravam no mercado de trabalho buscavam aperfeiçoamento profissional como estagiários, enquanto que os das regiões periféricas entraram no mercado de trabalho, em geral, mais novos, e estavam exercendo atividades de baixa remuneração, muitas vezes, sem carteira assinada, tais como, domésticas, babás, pedreiros, eletricistas e pintores.

Nesse sentido, os jovens das regiões centrais consideraram que a formação universitária propicia melhores chances de colocação no mercado de trabalho. Entende-se que esses jovens obtiveram a chamada 'moratória

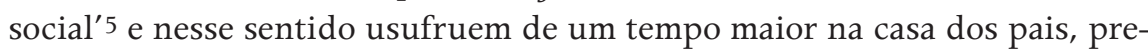
parando-se para o trabalho, o que por sua vez lhes permite maior liberdade de escolha (Aquino, 2009), como expressa o excerto a seguir: 
Eu faço estágio no clube Primeiro de Maio, trabalho com futebol (...). É o meu sonho, e tô no último ano de educação física. (...) Porque seu pai não vai ficar te bancando a vida toda. Então você precisa trabalhar pra ter o seu dinheiro. Um pouco de independência $(\mathrm{E} 78, \mathrm{C})$.

Me formar, conseguir um estágio, pra depois entrar em alguma emissora já fazendo jornalismo e (...) assim, depois estar em alguma emissora, ser um correspondente internacional $(\mathrm{E} 81, \mathrm{C})$.

Meus planos são terminar a minha faculdade, me formar como pedagogo, fazer pós-graduação, buscar seguir carreira na área educacional, me casar, que eu não sou casado ainda, constituir uma família e viver a vida, aproveitar os momentos bons e o que ela pode nos oferecer (E62, QC).

Pretendo fazer o máximo de cursos que eu puder, mais para frente fazer um curso lá fora e... tentar fazer contatos, trabalhar de freelancer para eventos, TV, esse tipo de coisas (E9, QC).

Já para os jovens das regiões mais periféricas, o trabalho responde às necessidades de reprodução social de suas famílias e, nesse sentido, apresentou-se muito precocemente para eles, na maioria das vezes em condições de subemprego, submetendo-os aos mecanismos advindos da articulação do capital com o Estado, que assume encaminhamentos neoliberais de desproteção ao mundo do trabalho (Antunes, 2000). Os jovens se submetem a tais condições de trabalho por serem vítimas do projeto econômico e político do neoliberalismo, já que seus pais, também submetidos à exploração, ocupam postos de trabalhos de baixa remuneração, o que não lhes permite manter seus filhos apenas estudando, repetindo-se assim o interminável ciclo de exclusão (Pochmann, 2005).

Corrochano (2002) alerta que jovens operários em indústrias do setor de autopeças da cidade de São Bernardo do Campo, que também faz parte da região do $\mathrm{ABC}$ paulista, apresentam idade média de ingresso no mercado de trabalho entre 14 e 15 anos. As principais ocupações não exigem qualificação, entre elas as de auxiliar de montagem, ajudante de produção, embalador e office-boy.

Revisão realizada por Fonseca (2010) sobre o trabalho infanto-juvenil no Brasil mostra que o fenômeno permanece funcional ao capital e que, no caso brasileiro, a reestruturação produtiva corrói os avanços representados pelo Estatuto da Criança e do Adolescente (ECA), mantendo e aprofundando o problema. 
De acordo com Branco (2005) e Sposito (2003), o trabalho precoce roubaria do jovem a possibilidade de conseguir melhor inserção, por meio de maior preparação, visto que a dedicação ao trabalho acaba por provocar atraso escolar. Dessa forma, neste estudo observa-se maior proporção de desempregados e maior preocupação com o desemprego na região P (37\% dos entrevistados desse grupo). São jovens com qualificação pouco ou não vendável, que dificilmente serão acionados pelos compradores de força de trabalho.

É difícil para a galera que tem 16, 17 anos arrumar um emprego, porque as empresas não estão fornecendo emprego. Eu acho que as empresas deveriam dar oportunidades, tipo para quem complete 18 anos também. As empresas estão exigindo experiência. De onde vai arrumar experiência se a pessoa nunca trabalhou? A pessoa tem que dar oportunidade para poder conseguir aquela pessoa (E26, P).

De forma geral, o trabalho, além do valor de status e de luta pela sobrevivência, está ideologicamente valorizado como uma agência de socialização responsável por manter os jovens longe dos perigos da 'cabeça vazia', sendo difundido um conjunto de ideias que pretende, a despeito de toda tragédia social mais ampla, retirar os jovens da ociosidade e dos descaminhos da rua, além de efetivamente responder às necessidades de reprodução social (Lachtim e Soares, 2009): "se não trabalhar, não tem direito a comer", "o trabalho dignifica o homem".

Porque lá na minha casa é que nem o meu pai falava: se não trabalhava, não comia. Quem não trabalhasse, então tinha que trabalhar... É um meio de sobrevivência $(\mathrm{E} 3, \mathrm{P})$.

O trabalho como agência de socialização aparece numa pesquisa realizada na Argentina, que mostra que os jovens valorizam mais as relações sociais, ficando por último a preocupação em ocupar o tempo ocioso.

El primer factor explica el 31,564\% de la varianza. Lo hemos denominado "desarrollo personal-social" ("relacionarse con la gente" 0,843; "aprender cosas nuevas" 0,778; "sentirse útil" 0,700; “ocupar el tiempo" 0,542) ya que agrupa aquellos ítems que hacen referencia a la salida exogámica que se manifiesta en la búsqueda de otros contactos sociales y de nuevos aprendizajes. Asimismo alude al desempeño de nuevos roles que favorecen una visión positiva de sí mismo (Aisenson et al., 2008, p. 76).

Nesse sentido, o caráter formador do trabalho, como 'escola da vida', e o temor dos pais de verem seus filhos 'aliciados pelas más companhias', 
é visto como protetor em alguma medida do jovem que trabalha, diminuindo o estigma que associa pobreza à criminalidade.

O caráter do trabalho está presente nos excertos a seguir:

(...) então, como eu já tenho outros amigos que teve [sic] outro tipo de juventude, diferente da minha, porque eu graças a Deus trabalhei sempre, desde os 14 anos que trabalho, então eu tive que desenvolver uma responsabilidade na minha vida. Agora, muitos amigos meus, que eu vejo hoje em dia, que não trabalhavam, que dependiam dos pais, muitos estão perdidos. Não aproveitam a juventude mais sadia. Por causa de muita... muita besteira, falta de responsabilidade, mesmo. Ah, tem, porque hoje em dia, no meu trabalho eu consegui me desenvolver profissionalmente muito fácil, vamos dizer assim, por trabalhar desde os 14 anos. Tem pessoas entrando no mesmo ramo que eu, que têm um pouco de dificuldade em questão desse desenvolvimento profissional. E o meu trabalho... isso mudou muito na minha estrutura familiar e pessoal. Influenciou totalmente na minha vida, tá (E21, QC).

Ah, comecei trabalhar... assim, que foi uma tentativa dos meus pais de me tirar um pouco da rua, porque eu também queria sair um pouco da rua, pra assumir mais responsabilidades, ter dinheiro, comprar um carro. Essas coisas... Ah, acho que ninguém gosta muito, né? De trabalhar. Mas é uma coisa necessária, né? Na vida que todo mundo tem que trabalhar. Vai de se a pessoa trabalha no que gosta ou não (E76, QC).

Contudo, Sarti (2003) faz uma crítica a esse valor positivo do trabalho:

É através do trabalho, então, que demonstram não serem pobres: através de sua honestidade, sua disposição a vencer, tornam-se, por esses atributos morais, iguais a eles. Vencer aqui não significa necessariamente ascender socialmente, mas se afirmar pelo valor positivo do trabalho. Ao lado da negatividade contida na noção de ser pobre, a noção de ser trabalhador dá ao pobre uma dimensão positiva, inscrita no significado moral atribuído ao trabalho, a partir de uma concepção da ordem do mundo social que requalifica as relações de trabalho sob o capital (...). O valor moral atribuído ao trabalho compensa as desigualdades socialmente dadas, na medida em que é construído dentro de outro referencial simbólico, diferente daquele que desqualifica socialmente (Sarti, 2003, p. 89).

Além do valor protetor do trabalho, como agência de socialização, os jovens valorizam o trabalho como elemento para se conquistar dignidade e honestidade. Tal sentido aparece mais fortemente nos grupos periféricos.

(...) aí quando eu comecei no serviço era cedo então, não faltava, comecei a me dedicar pro serviço, aí eu fui ficando. Eu sempre tive vontade de ter as coisas, sabe? 
E meu pai não tinha condições de dar e eu corri atrás. Também hoje tenho tudo o que quero. De entregar folheto. Aí, trabalhei um ano lá, de entregar folheto, e depois fiquei um ano entregando comida de moto, depois trabalhei mais um ano no pet shop, e agora três anos de cobrador de ônibus. [Trabalho] Uma das primeiras coisas que tem pro homem (E 37, QP).

Olha, eu comecei a trabalhar que eu tinha 12 anos. Eu trabalhei em uma cantina com a minha irmã, depois trabalhei em uma padaria. Aí eu fiquei grávida, fiquei uns seis anos... cinco anos sem trabalhar. Aí resolvi voltar, trabalhei em uma pizzaria, tudo... depois parei, e agora voltei. Faxineira [gargalhada]... Ah, não é legal, né, mas é bom porque a gente tem um dinheiro, né? É um trabalho digno, honesto, mas... não é legal (E28, P).

Nesta pesquisa foram raras as críticas dos jovens ao atual modelo de organização do trabalho, que exige um trabalhador polivalente, capaz de desempenhar diferentes tarefas ao longo do processo de trabalho. Difundese o ideário de que para tanto se requer maior qualificação, de forma que os trabalhadores não se tornem obsoletos e descartáveis para a empresa. Para quem está prestes a ingressar no mercado de trabalho, como é o caso dos jovens, este esforço em se qualificar seria recompensado por uma vaga ou mesmo uma ascensão a curto prazo, desde que o trabalhador realize um grande esforço individual e tenha muita dedicação (Sennett, 2008).

No excerto a seguir, um jovem expõe a contradição entre os sentidos positivos e negativos que atribui ao trabalho.

Eu sou professor de educação básica, professor de história. Sou mestrando do Programa de Mestrado em Educação da Uninove. (...) Faço (...) curso de inglês. Trabalho desde os meus 15 anos (...) meu primeiro emprego foi atendente do McDonalds Comércio de Alimentos. Sentido de ter contato com o que é o trabalho, o que é uma renda, o que é um holerite, o que são responsabilidades, questões de horário, é, higiene pessoal, higiene mental, controle, é, felicidade, ética, compromisso e verdade (...). Ao mesmo tempo, também, contato com os direitos e deveres do trabalhador. Sindicato, essas coisas. Eu (...) vejo o trabalho como a (...) uma opressão; o trabalhador, ele vende a sua força de trabalho, ele vende, e infelizmente essa força de trabalho, ela é comprada por um preço muito baixo, muito pequeno, e aí você tem aquelas questões de mais-valia (...) não que eu seja marxista, mas (...) eu tô indo por essa linha (...) eu vejo o trabalho como uma faca de dois gumes: por um lado você é explorado (...) e por outro lado você cria responsabilidades, você entra num universo (...) paralelo (...) um paradoxo. Você é explorado e ao mesmo tempo você trabalha, tem uma renda, você pode utilizar esse dinheiro para fins culturais (...) crescimento pessoal, crescimento familiar. Subjetivo (E82, C). 
Embora as críticas tenham sido poucas, o sofrimento consequente à reestruturação produtiva foi captado nas falas dos jovens. Segundo Lachtim e Soares (2009), essa ideologia induz o jovem a se culpabilizar por não conseguir acessar o mercado de trabalho, uma vez que não investiu o necessário na sua formação profissional e, portanto, precisa se colocar à mercê do mercado, para manutenção de suas famílias e/ou de seus projetos de vida. Nesse sentido, a tentativa do jovem em investir na escolaridade, para escapar desse 'fantasma da inutilidade', também foi captada:

Ah, porque é difícil, a gente não arruma emprego, principalmente quando a gente não tem estudo, né? A gente não arruma emprego fácil. Eu cuido de uma senhora... (E65, P).

Aí é complicado porque muitos jovens não conseguem o primeiro emprego, não têm oportunidade. Empresas instaladas aqui no ABC, elas preferem contratar profissionais com experiência. Nas próprias escolas não tem preparo, não tem o ensino sólido para você passar em uma faculdade para você ter um futuro digno, o que mais? É difícil, é difícil (E18, QC).

Estudo canadense sobre políticas de inserção assistida no trabalho mostra a existência de um discurso social amplo, que reduz o problema do emprego à dimensão individual, o que contribui para a 'auto(estigmatização)' do grupo que apresenta dificuldades de inserção no mercado de trabalho (Vultur, 2005).

Contribui ainda para responsabilizar o jovem individualmente sobre as dificuldades de enfrentar o mercado de trabalho a ideologia da chamada 'sociedade do conhecimento', que considera que a riqueza está no conhecimento, um 'conhecimento útil', que supostamente poderia ser disseminado para todos, ainda que, reconheça-se, em ritmos diferentes (Alves e Batista, 2010). Dessa forma, o fantasma da necessidade de mais qualificação para resolver o problema da inserção no mercado de trabalho ajuda a mascarar a essência da exploração capitalista, que afeta os jovens mais significativamente, pois são eles que acabam por enfrentar os maiores índices de desemprego e aceitar colocações precárias do trabalho (Sposito, 2003). Nesta pesquisa foram os jovens dos grupos sociais mais explorados que acabaram se ressentindo mais da crise estrutural do emprego.

(...) eu comecei a trabalhar nova... com 14 anos, eu estava precisando (...) dinheiro para comprar as minhas coisas, e é isso. Bom... o trabalho que eu estou não é o trabalho dos meus sonhos. Por isso estou estudando para ter uma coisa melhor (...). Para ver se Deus me ajuda que eu consiga uma coisa melhor, para meu futuro. É isso. Eu acho que trabalhar cedo é muito importante, sim. Que aí a pessoa tem mais 
experiência, assim, mais conhecimento de vida. Aprende a ter responsabilidade mais cedo $(\mathrm{E} 72, \mathrm{P})$.

Do ponto de vista do discurso dos jovens entrevistados nesta pesquisa, o trabalho traz uma expectativa de conseguir autonomia e responsabilidade frente às exigências do mundo adulto, mediante a aquisição de novas habilidades e conhecimento, advindas da escola. Pesquisa realizada com jovens argentinos confirma esse sentido do trabalho.

El trabajo adquiere relevancia como actividad si permite desarrollar nuevos roles y habilidades, adquirir conocimientos, confianza en si mismo y la consecuente autonomía, en el marco de la transición que los jóvenes afrontan hacia nuevas experiencias personales (Aisenson et al., 2008, p. 78).

A ideologia liberal sobre a inserção no trabalho ganha reforço com a apologia ao autonegócio e ao empreendedorismo (Frigotto, 2011).

De forma geral, os jovens veem no fruto do trabalho o sucesso que almejam para suas vidas e de suas famílias. O trabalho apresenta, portanto, um importante valor para atingir metas, planos e projetos futuros. A mobilidade social é uma das metas a ser conquistada através do trabalho. Acredita-se na ideologia difundida que o esforço individual é responsável pela ascensão social (Telles, 1990; Bianchetti, 1997).

(...) eu, terminar a faculdade, começar o mestrado o mais breve possível para poder dar aula. Eu não pretendo dar aula durante vinte anos, pelo menos, eu não quero dar aula. Mas é um negócio que eu acho que se um dia eu ficar desempregado, você consegue aula na universidade, sem muita dor de cabeça, então, assim, pensando no futuro. E nesse meio-tempo eu pretendo continuar na empresa que eu estou, e crescer nessa área. Talvez ir para uma área gerencial ou... é... talvez ir para uma área gerencial. Sair um pouco da área técnica e ir mais para a área de quem especifica o que fazer, que mexe mais com o cérebro (E5, C).

(...) meu plano assim para curto prazo primeiro é arranjar um emprego na área que estou pretendendo. Como também sou técnica em nutrição, então minha pretensão é conciliar pedagogia com a nutrição infantil, então, voltada sempre para o público infantil. A longo prazo é conseguir um dia ter a minha escola, né?, devolver isso melhor (E17, QC).

(...) procurar um objetivo melhor, um serviço melhor... Pretendo fazer uns cursos, para aprender algumas coisas que eu gosto, que eu acho legal... Ah... uns cursos de... informática já tenho aqui. Mas pretendo fazer mais, inglês, que é muito interessante e que pede bastante quando vai procurar serviço. E... hum... eh... de enfer- 
magem... ah... sonho alto... só sonho... de enfermagem... operadora de máquinas, uns cursos aí, tem que fazer... até arrumar um serviço que eu falar - vou mandar um currículo aí que eu sei...--, que eu tenha certeza que possam me chamar, né? Ter a minha casa... E eu não quero aqui, não, eu quero na Bahia... Ah... mais o quê... Viajar, conhecer Porto Seguro e conhecer Campos de Jordão. Ah, um monte de coisas... coisinhas assim... tudo... (E42, QP).

(...) então eu voltei a estudar, porque tinha parado, né... Então, como parei, voltei agora, para poder ter oportunidade mais para frente, né? Eu pretendo fazer uns cursos, fazer uma faculdade, alguma coisa. Porque o futuro agora... tem que correr atrás... por causa das oportunidades de trabalho. Está fácil para quem é estudado, para quem tem cursos. Mas para quem não tem estudo está muito difícil, eu acho (E24, P).

Dessa forma, os jovens associam o futuro a uma colocação no mercado de trabalho, e estão convencidos de que tal colocação passa obrigatoriamente pelo aumento dos anos escolares e pela busca por ensino profissionalizante. Como já discutido anteriormente, são medidas que necessariamente são exigidas pelo mercado, porém não garantem os postos de trabalho, mesmo porque continua a haver uma desproporção entre a idade e os anos escolares ocasionada por percursos escolares irregulares (Aquino, 2009).

\section{Conclusão}

Os resultados deste trabalho indicam haver semelhanças e diferenças nos valores atribuídos ao trabalho pelos jovens de diferentes grupos sociais.

Apesar das diferenças marcantes quanto à idade de início, aos motivos do trabalho e ao uso da renda proveniente do trabalho, é possível afirmar que, em todos os grupos, os jovens cultivam valores positivos sobre o trabalho. Sua positividade não se encontra alicerçada no desenvolvimento das potencialidades humanas e na satisfação de necessidades sociais mais amplas de realização da liberdade e da criatividade, mas encontra-se fundamentada nas necessidades de reprodução social, seja para a manutenção da força de trabalho, seja para a reprodução dos meios de produção.

Entre as diferenças, pode-se concluir que nos grupos de jovens que usufruem dos bens produzidos socialmente o trabalho é valorizado porque permite a continuidade desse usufruto, o acúmulo de capital e a melhora de status social, o que por sua vez constitui valor de realização no capitalismo. Já entre os jovens dos grupos que apresentam dificuldades de reprodução social, o trabalho seria o mecanismo mesmo para sua manutenção. 
Os planos de futuro dos jovens de todos os grupos se associam à inserção no mundo adulto, sendo o trabalho seu principal objeto de preocupação, seja para conquistar um emprego seja para galgar melhores colocações no mercado. $\mathrm{O}$ fato é que o que efetiva o consumo é a renda advinda do trabalho, neste estão depositados outros sonhos como ter independência financeira ou formar uma família.

As diferenças apontadas pelos grupos, quando indagados sobre o futuro, referem-se às trajetórias por eles desenhadas: os jovens das regiões centrais têm planos de continuar cursando o ensino superior, fazer uma pósgraduação, com possibilidade de morar no exterior; apresentam preocupação com a colocação no mercado de trabalho e com o aprimoramento acadêmico, necessário para efetivar esse projeto de vida, que por sua vez associa-se à autonomia financeira. Neste momento da vida, podem consumir a cultura jovem (roupas, baladas e viagens) e manter os planos escolares. São projetos de vida formulados de forma individual, com um trajeto bem definido, que não parece estar sujeito a grandes rupturas ou descontinuidades. Já para os jovens dos grupos sociais das regiões periféricas, os planos são de melhorar a escolaridade, muitos almejando inclusive frequentar uma universidade, porém conscientes da inconsistência desse projeto, pois na prática conseguem frequentar, no melhor dos casos, cursos profissionalizantes, oferecidos sob condições que tornam possível ter uma jornada de trabalho exaustiva e estudar concomitantemente. No extremo, confessam-se totalmente deslocados e o quanto se sentem inseguros para pensar o futuro.

Os jovens atribuíram ao trabalho valores de cunho notadamente liberal, representados pela ideologia da 'sociedade do conhecimento', da qualificação formal e técnica para o trabalho, da competência profissional e da apologia à autonomia. Tal ideologia mascara as diferenças de classe, que se encontram na raiz da divisão técnica do trabalho, e dissimula também as contradições do regime de acumulação e da crise estrutural do emprego. Assim, os jovens entrevistados das regiões periféricas, mesmo concretamente vivenciando realidades duras de reprodução social, parecem acreditar que basta se qualificar para encontrar uma boa colocação no mercado de trabalho, assumindo para si o ônus da competência para vender no mercado sua força de trabalho.

Observou-se que o valor atribuído ao trabalho está fortemente vinculado à venda da força de trabalho por salário, e que o valor ontológico do trabalho incluindo o princípio educativo, ético, político e necessário para a manutenção da sociedade humana - não foi em geral reconhecido pelos jovens.

A valorização da educação se dá pela via da escola formal e do 'conhecimento útil' para a qualificação profissional. Os valores históricos de formação humana ampla e de transmissão da cultura acumulada não são cultivados pelos jovens dos diferentes grupos. Contribui para isso uma formação acrítica e alinhada com os interesses do capital, de forma que no lugar de 
alertar os jovens nas escolas e em outros espaços de formação sobre as contradições capitalistas, as instituições sociais majoritariamente perpetuam a ideologia de sustentação da divisão social do trabalho.

Nossa proposta, diante desses resultados, não poderia ser outra senão a de alertar os jovens nos diversos espaços da vida social, de educação formal ou não, quanto às contradições reais que se encontram na base da realidade de trabalho, componente fundamental do tipo de futuro que lhes está reservado. A perspectiva de educação emancipatória, que nasce a partir da contribuição de diversos autores filiados à vertente histórico-crítica, tem se mostrado potencialmente capaz de contribuir para produzir críticas necessárias à transformação de práticas sociais educativas (Soares, Campos, Berto, Pereira, 2011).

\section{Nota do Editor}

Este artigo trata de uma parte da pesquisa de mestrado intitulada "Jovens de Santo André, SP, Brasil: um estudo sobre valores em diferentes grupos sociais", de autoria de Sheila Aparecida Ferreira Lacthim, orientada por Cássia Baldini Soares, com financiamento da Fundação de Amparo à Pesquisa do estado de São Paulo. (processo Fapesp n. 06-51671-9). Não há conflito de interesses.

\section{Notas}

1 Enfermeira da Estratégia Saúde da Família no município de São Paulo, pela Associação Saúde da Família, São Paulo, SP, Brasil. Mestre em Ciências pela Escola de Enfermagem da Universidade de São Paulo (USP). <shamf@usp.br>

Correspondência: Universidade de São Paulo, Departamento de Enfermagem em Saúde Coletiva, Av. Dr. Enéas de Carvalho Aguiar, 419, sala 233, 2. ${ }^{\circ}$ andar, Cerqueira Cesar, CEP 05403-000, São Paulo, SP, Brasil, Caixa postal 41633.

2 Professora associada do Departamento de Enfermagem em Saúde Coletiva da Universidade de São Paulo (USP), São Paulo, SP, Brasil. Doutora em Educação pela Universidade de São Paulo. <cassiaso@usp.br>

3 De acordo com a OIT, 'trabalho decente' refere-se a um "trabalho produtivo adequadamente remunerado, exercido em condições de liberdade, equidade e segurança, sem 
quaisquer formas de discriminação e capaz de garantir uma vida digna a todas as pessoas que dele extraem o seu sustento" (Costanzi, 2009, p. 171).

4 No Brasil, em 2006 a taxa geral de desemprego para os jovens era de 17,8\%, cerca de 3,2 vezes superior à dos adultos e 2,1 vezes superior à taxa geral de desemprego. Um total de 3,9 milhões de jovens estava desempregado nesse ano. Embora os jovens representassem $23,2 \%$ da PEA, respondiam por apenas $20,8 \%$ da ocupação total e por quase metade $(49,1 \%)$ dos desempregados (Costanzi, 2009).

5 De acordo com Aquino (2009, p. 26), “o termo moratória social foi cunhado por Erik Erikson no fim da década de 1950 e atualizado décadas depois por Mario Margulis e Marcelo Urresti (...). Na sociologia da juventude, a ideia de moratória social associa-se às transformações ocorridas desde o início do século XX, no modelo de socialização dominante na Europa ocidental, sobretudo entre as famílias burguesas (...). Em certo sentido, este período representa uma oportunidade para o ensaio e o erro, para experimentações (...)."

\section{Referências}

ALVES, Giovanni; BATISTA, Roberto Leme O fetiche do capital intelectual: a ideologia do conhecimento e da adaptação no contexto da reestruturação produtiva do capital. Revista HISTEDBR (on line), Campinas, n. esp., p. 154-174, ago. 2010.

AISENSON, Diana et al. El sentido del estudio y el trabajo para los jóvenes que finalizan la escuela de nivel medio: un análisis desde la perspectiva de la psicología de la orientación. Facultad de Psicología-UBA/Secretaría de Investigaciones. Anuario de Investigaciones, Buenos Aires, v. XV, p. 71-80, 2008.

ALMEIDA, Elmir; VILLAR, Maria Elena. Ações públicas para a juventude de governos locais do Grande ABC: descompassos entre trajetórias. In: REUNIÃO ANUAL DA ANPED, 28., Caxambu, MG, GT Movimento Sociais, 2005.

ANTUNES, Ricardo. Os sentidos do trabalho: ensaio sobre a afirmação e a negação do trabalho. São Paulo: Boitempo, 1999.

Adeus ao trabalho? Ensaio sobre as metamorfoses e a centralidade do mundo do trabalho. 7. ed. São Paulo: Cortez, 2000.
O caráter polissêmico e multifacetado do mundo do trabalho. Trabalho, Educação e Saúde, Rio de Janeiro, v. 1, n. 2, p. 53-61, 2003.

AQUINO, Luseni Maria Cordeiro de. Introdução: a juventude como foco das políticas públicas. In: CASTRO, Jorge Abrahão de; AQUINO, Luseni Maria Cordeiro de, ANDRADE, Carla Coelho de. Juventude e politicas sociais no Brasil. Brasília: Instituto de Pesquisa Econômica Aplicada (Ipea). 2009. $303 \mathrm{p}$.

BARDIN, Lawrence. Análise de conteúdo. Tradução de Luís Antero Neto e Augusto Pinheiro. Lisboa: Edições 70, 1977.

BIANCHETTI, Roberto G. Modelo neoliberal e políticas educacionais. São Paulo: Cortez, 1997.

BRANCO, Pedro Paulo Martoni. Juventude e trabalho: desafios e perspectivas para as políticas públicas. In: ABRAMO, Helena Wendel; BRANCO, Pedro Paulo Martoni (Orgs.). Retratos da juventude brasileira: análise de uma pesquisa nacional. São Paulo: Fundação Perseu Abramo, 2005. p. 129-148. 
CORROCHANO, Maria Carla. Jovens olhares sobre o trabalho. Trabalho apresentado no GT Trabalho e Educação. In: REUNIÃO ANUAL DA ANPED, 25. Anped, 25 anos. 2002. CDROM.

COSTANZI, Rogério Nagamine. Trabalho decente e juventude no Brasil. Brasília: Organização Internacional do Trabalho, 2009. 220p.

FONSECA, Laura Souza. Trabalho infantojuvenil e formação humana: limites na potência ontológica e banalização do sujeito de direitos. Trabalho, Educação e Saúde, Rio de Janeiro, v. 8, n. 1, p. 137-153, mar./jun. 2010.

FRIGOTTO, Gaudêncio. Concepções e mudanças no mundo do trabalho e o ensino médio. Centro de Educação Tecnológica do Estado da Bahia (Ceteb). s/d. Disponível em: $<$ www.ia.ufrrj.br/ppgea/conteudo/conteudo-2008-2/Educacao-MII/2SF/2-Frigoto 2008 .pdf $>$.Acesso em: 2011.

FRIGOTTO, Gaudêncio; CIAVATTA, Maria. Educar o trabalhador cidadão produtivo ou o ser humano emancipado? Trabalho, Educação e Saúde, Rio de Janeiro, v. 1, n. 1, p. 45-60, 2003.

LACHTIM, Sheila Aparecida Ferreira; SOARES, Cássia Baldini. Trabalho de jovens estudantes de uma escola pública: fortalecimento ou desgastes? Revista Brasileira de Enfermagem, Brasília, v. 62, n. 2, p. 179-186, 2009.

LESSA, Sergio. Trabalho, sociabilidade e individuação. Trabalho, Educação e Saúde, Rio de Janeiro, v. 4, n. 2, p. 231-246, 2006.

POCHMANN, Márcio et al. Atlas da exclusão social no Brasil. São Paulo: Cortez, 2005.
SARTI, Cynthia Andersen. A família como espelho: um estudo sobre a moral dos pobres. São Paulo: Cortez, 2003.

SENNETT, Richard. A cultura do novo capitalismo. Rio de Janeiro: Record, 2008.

SOARES, Cassia Baldini; CAMPOS, Célia Maria Sivalli; BERTO, Juliana Sette; PEREIRA, Érica Gomes. Avaliação de ações educativas sobre consumo de drogas e juventude: a práxis no trabalho e na vida. Trabalho, Educação e Saúde (Impresso), Rio de Janeiro, v. 9, p. 41-60, 2011.

SPOSITO, Marília Pontes. Os jovens no Brasil: desigualdades multiplicadas e novas demandas políticas. São Paulo: Ação Educativa, 2003.

TELLES, Vera da Silva. A pobreza como condição de vida: família, trabalho e direitos entre as classes trabalhadoras urbanas. São Paulo em Perspectiva, São Paulo, v. 4, n. 2, p. 37-45, abr./jun., 1990.

TRIVIÑOS, Augusto Nibaldo da Silva. Introdução à pesquisa em ciências sociais: a pesquisa qualitativa em educação. São Paulo: Atlas, 1987.

VIANA, Nildo. Os valores na sociedade moderna. Brasília: Thesaurus, 2007.

VULTUR, Mircea. Os jovens e os programas de inserção profissional no Quebec: entre a lógica do ator e a normatividade institucional. In: CASTRO, Lucia Rabello de; CORREA, Jane. Juventude contemporânea: perspectivas nacionais e internacionais. Rio de Janeiro: Faperj, 2005. p. 203-229.

YONEKURA, Tatiana et al. Mapa das juventudes de Santo André. Revista de Saúde Pública, São Paulo, v. 4, n. 1, p. 45-52, 2010.

Recebido em 25/05/2010

Aprovado em 13/07/2011 
No artigo "Valores atribuídos ao trabalho e expectativa de futuro: como os jovens se posicionam?", de Sheila Aparecida Ferreira Lachtim e Cássia Baldini, publicado no fascículo 2 do volume 9, p. 277-293, foi omitida uma referência, que publicamos a seguir, correspondente à citação (Frigotto, 2011), na pág. 288, segundo parágrafo:

FRIGOTTO, Gaudêncio. Concepções e mudanças no mundo do trabalho e o ensino médio. Centro de Educação Tecnológica do Estado da Bahia (Ceteb). s/d. Disponível em: $<$ www.ia.ufrrj.br/ppgea/conteudo/conteudo2008-2/Educacao-MI/2SF/2-Frigotto2008.pdf>. Acesso em: 2011. 